Special issue of the 3rd International Conference on Computational and Experimental Science and Engineering (ICCESEN 2016)

\title{
The Theoretical Production of In Isotopes by Insertion of Alpha Particles into Cd Nucleus
}

\author{
F. KiLInÇ ${ }^{a}$, B. Çetin ${ }^{a}$ AND N. KARPUZ ${ }^{b, *}$ \\ ${ }^{a}$ Amasya University, Sciences and Arts Faculty, Amasya, Turkey \\ ${ }^{b}$ Amasya University, Sabuncuoğlu Şerefeddin Health Services, Vocational School, Amasya, Turkey \\ Knowledge of the cross sections of reactions of charged particles with target material is needed to understand \\ well the mechanisms of nuclear reactions. One of the main application fields of nuclear technology and nuclear \\ reactions is medicine. Radioisotopes are used in medicine and production of these radioisotopes is important. \\ In the production processes, the cross sections must be known. For this purpose, in this study, theoretical cross \\ sections of production of In isotopes by alpha irradiation have been calculated using Talys 1.6 nuclear reaction \\ simulation code. The obtained results are compared with the existing experimental data.
}

DOI: 10.12693/APhysPolA.132.1080

PACS/topics: 13.85.Lg, 13.87.Ce, 25.60.Dz

\section{Introduction}

Cross section measurements of nuclear reactions, reactor technology and nuclear structure studies are needed in many areas. Cross section is a measure of the relative probability of reaction occurrence.

Evolving detector technologies with increasing sensitivity allow better cross-section measurements and thus nuclear data tables are updated on a continuous basis through out the world. Since energy is a value which influences the reaction cross section, different energy regions are of great importance in different branches of physics.

First cross section measurements related to 106Cd(a,p)In-109 reaction were carried out at Brookhaven National Laboratory in the United States of America in 1965. Measurements were carried out using cyclotron. This study was carried out in $17.9-31 \mathrm{MeV}$ energy range, by accelerating the alpha particles into $\mathrm{Cd}$ target material. Measured cross-section at $22.3 \mathrm{MeV}$ was found to be $243 \mathrm{mb}$ [1].

First measurements of $114-\mathrm{Cd}(\mathrm{a}, \mathrm{p}) \mathrm{In}-117$ reaction cross section was carried out in 2008 at Vrije University in Brussels, Inst. of Nuclear Research and at Babes-Bolyai University. Measurements were carried out using cyclotron. In this study alpha particles with energy in range of $21-38 \mathrm{MeV}$ were sent to $\mathrm{Cd}$ target material. Measured cross-section at 27.6 MeV has been found to be $9.4 \mathrm{mb}$ [2].

Different studies have been using Talys code for calculation of nuclear reaction cross sections. $(\gamma, \mathrm{n})$ and $(\gamma, \mathrm{p})$ reaction cross sections were calculated for ${ }^{28} \mathrm{Si}$, ${ }^{32} \mathrm{~S},{ }^{56} \mathrm{Fe}$ and ${ }^{63} \mathrm{Cu}$ targets in [3]. In another study, for the reactions of ${ }^{10} \mathrm{~B}(\mathrm{a}, \mathrm{n}){ }^{13} \mathrm{~N}$ and ${ }^{16} \mathrm{O}(\mathrm{a}, \mathrm{np}){ }^{18} \mathrm{~F}$, production cross section values were calculated in the energy range between 0.5 and $100 \mathrm{MeV}$ [4]. In [5], production

*corresponding author; e-mail: nurdankarpuz@amasya.edu.tr cross sections for the reactions of ${ }^{100} \mathrm{Mo}(\mathrm{p}, 2 \mathrm{n}){ }^{99} \mathrm{Tc}$, ${ }^{58} \mathrm{Fe}(\mathrm{p}, 2 \mathrm{n}){ }^{57} \mathrm{Co}$ and ${ }^{112} \mathrm{Cd}(\mathrm{p}, 2 \mathrm{n}){ }^{111} \mathrm{In}$ were calculated in the energy range between 1 and $100 \mathrm{MeV}$.

\section{Method}

${ }^{109} \mathrm{In},{ }^{117} \mathrm{In}$ are the radioisotopes used in nuclear medicine. ${ }^{106} \mathrm{Cd}$ and ${ }^{114} \mathrm{Cd}$ isotopes can be used as target materials for the production of ${ }^{109} \mathrm{In}$ and ${ }^{117} \mathrm{In}$ radioisotopes. These radioisotopes are used in kidney imaging.

In this study, the cross section of ${ }^{106} \mathrm{Cd}(\mathrm{a}, \mathrm{p}){ }^{109} \mathrm{In}$ and ${ }^{114} \mathrm{Cd}(\mathrm{a}, \mathrm{p}){ }^{117} \mathrm{In}$ reactions was calculated. The calculations were carried out using Talys 1.6 program by Monte Carlo simulation of nuclear reactions. Talys is a nuclear reaction simulation computer code for the analysis and prediction of nuclear reactions, written in FORTRAN programming language and running on Linux operating system. Talys 1.6 [6] performs calculations in $1 \mathrm{keV}-$ $1 \mathrm{GeV}$ energy range of the protons, neutrons, deuterons, tritons, gamma, alpha and $3 \mathrm{He}$ particles with a mass of 12 and more by examining their interaction with the atomic cores.

\section{Results}

The calculated ${ }^{106} \mathrm{Cd}(\mathrm{a}, \mathrm{p}){ }^{109} \mathrm{In},{ }^{114} \mathrm{Cd}(\mathrm{a}, \mathrm{p}){ }^{117} \mathrm{In}$ production reaction cross sections are shown in Figs. 1 and 2. The obtained results have been compared with the experimental data existing in the EXFOR [7] data bases. During the preceding years there were some studies of the theoretical cross sections [8-14] using Talys 1.6 nuclear reaction simulation code.

\section{Conclusions}

The cross section of $(a, p)$ reaction was examined for the 0.5-100 MeV energy range using Talys 1.6 code (Fig. 1). No reaction was observed below the energy value of about 8.5 MeV. An increase of reaction cross section was observed up to energy of $21 \mathrm{MeV}$, which is the first maximum 


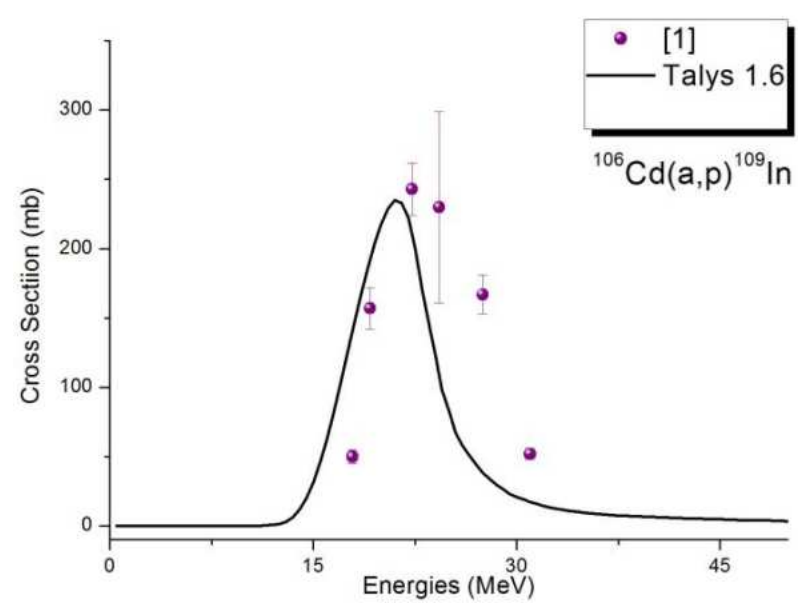

Fig. 1. The calculated cross sections of ${ }^{106} \mathrm{Cd}(\mathrm{a}, \mathrm{p}){ }^{109} \mathrm{In}$ reaction and comparison with experimental results.

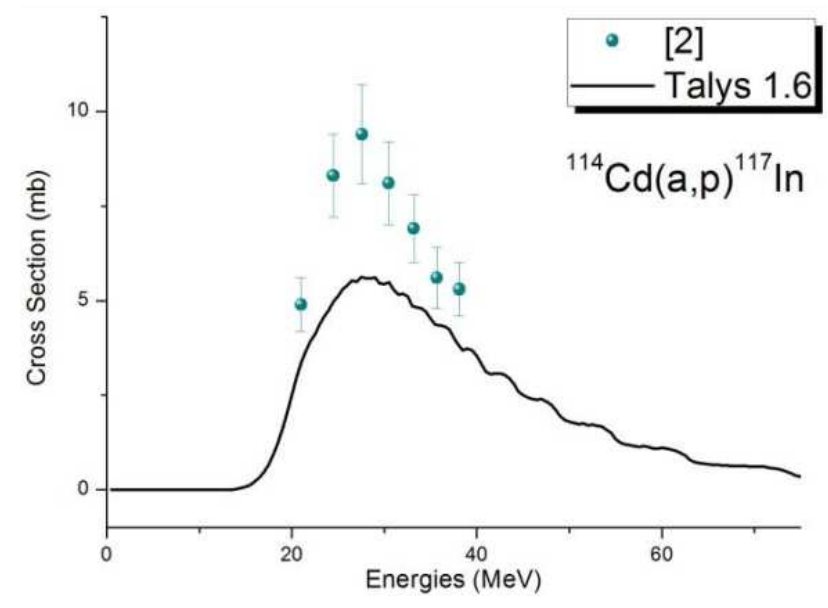

Fig. 2. The calculated cross sections of ${ }^{114} \mathrm{Cd}(\mathrm{a}, \mathrm{p}){ }^{117} \mathrm{In}$ reaction and comparison with experimental results.

point. The cross section value at the first maximum point is $234.994 \mathrm{mb}$. The most appropriate production range for ${ }^{106} \mathrm{Cd}(\mathrm{a}, \mathrm{p})^{109} \mathrm{In}$ nuclear reaction is between 15 and $30 \mathrm{MeV}$. The theoretical results obtained with Talys 1.6 code are compatible with values from the literature.

The cross section of $(a, p)$ reaction was examined for the 0.5-100 MeV energy range using Talys 1.6 code (Fig. 2). No reaction was observed below the energy value of about $11 \mathrm{MeV}$. An increase of reaction cross section was observed up to energy of $27.5 \mathrm{MeV}$, which is the first maximum point. The cross section value at the first maximum point is $5.50587 \mathrm{mb}$. Above the energy of $28 \mathrm{MeV}$ there are small oscillations. The most appropriate production range for ${ }^{114} \mathrm{Cd}(\mathrm{a}, \mathrm{p}){ }^{117} \mathrm{In}$ nuclear reaction is $20-40 \mathrm{MeV}$. The theoretical results obtained with Talys 1.6 code are compatible with values from the literature.
Reaction cross sections for production of ${ }^{109} \mathrm{In}$ and ${ }^{117}$ In medicine radioisotopes were calculated theoretically. The calculated results were compared with the experimental data from the literature. It is seen that the theoretical results, calculated using the Talys 1.6 program, are compatible with the experimental data.

\section{References}

[1] R.L. Hanh, Phys. Rev. 137, B1491 (1965).

[2] R.A. Rebeles, A. Hermanne, P. Van Den Winkel, F. Tarkanyi, S. Takacs, L. Daraban, Nucl. Instrum. Meth. Phys. Res. 266, 4731 (2008).

[3] N. Karpuz, M.C. Boz, B. Mavi, İ. Akkurt, Acta Phys. Pol. A 128, B-411 (2015).

[4] F. Kılınç, B. Çetin, N. Karpuz, AIP Conf. Proc. 1815, 130006 (2017).

[5] F. Kılınç, N. Karpuz, B. Çetin, Acta Phys. Pol. A 130, 311 (2016).

[6] A. Koning, S. Hilaire, S. Goriely, Talys-1.6 A Nuclear Reaction Program, User Manual, NRG, 2013.

[7] EXFOR/CSISRS, Experimental Nuclear Reaction Data File, Brookhaven National Laboratory, National Nuclear Data Center, 2009.

[8] N. Karpuz, B. Mavi, Acta Phys. Pol. A 130, 304 (2016).

[9] N. Karpuz, B. Mavi, İ. Akkurt, Acta Phys. Pol. A 130, 313 (2016).

[10] F. Kilinç, N. Karpuz, B. Çetin, Acta Phys. Pol. A 130, 318 (2016).

[11] S.S. Noori, N. Karpuz, İ. Akkurt, Acta Phys. Pol. A 130, 484 (2016).

[12] N. Karpuz, M.C. Boz, B. Mavi, F. Öner, İ. Akkurt, Acta Phys. Pol. A 128, B-363 (2015).

[13] N. Karpuz, M.C. Boz, B. Mavi, I. Akkurt, Acta Phys. Pol. A 128, B-409 (2015).

[14] N. Karpuz, B. Mavi, İ. Akkurt, Acta Phys. Pol. A 128, B-414 (2015). 